\title{
PARTICIPAÇÃO DOS POVOS INDÍGENAS NA CONFERÊNCIA EM DURBAN
}

\author{
ELIANE POTIGUARA
}

Rede de Comunicação Indígena sobre Gênero e Direitos

\section{Juçara: o início da solidão e do sofrimento das mulheres indígenas, motivados pela violência e pelo racismo}

Muitas famílias indígenas foram separadas pelas invasões estrangeiras. Invasões do passado, invasões do presente, invasões do futuro. No passado, as frentes de expansão econômica, as frentes missionárias, as frentes de dtraçăloêram as causas das transformações sociais das populações indígenas. Em/763, varicela, escarlatina, varíola, sarampo, gripe e tuberculose fizeram 7,414 vítimas! O padre Fernandez escreveu em um de seus relatórios que os portugueses e os mamelucos de São Paúlo tinham assassinado, em 130 anos, 2 milhões de índios guarani nas bacias dos rios Paraná, Paraguai e Uruguai. Muitos desses indígenas vieram capturados para São Paulo, o Rio de Janeiro e até o Nordeste brasileiro. Em 1729, a chamada República Guarani somava um fotal de 131.658 indígenas escravizados. Os exércitos português e espanhol, na batalha de 7 de fevereiro de 1756 , próximo a Bagé (sudoeste do Rio Grande do Sul), assassinaram Sepé Tiaraju e mais 10 mil guaranis. Sua esposa, Juçara, levaria às costas a menina recém-nascida que Sepé jamais veria. Era o início da solidão e do sofrimento das mulheres, motivados pela violência, pelo racismo e por todas as formas de intolerância, inclusive referentes à espiritualidade e à cultura indígenas.

Durante o processo de escravidão indígena, muitos pais e famílias cometiam o suicídio em massa contra essa forma de opressão. Atiravam-se dos penhascos. Isso era um ato de resistência. Nesse caso, percebemos que muitas famílias sofreram a separação, e é a esse enfoque que nos reportamos. Entre as causas da separação das famílias estão a violência aos territórios imemoriais dos povos indígenas e a migração compulsória. Isso provocou insegurança familiar, medo e pânico, causando loucura, violências interpessoais, suicídios, alcoolismo, timidez e a baixa auto-estima diante do mundo. Tudo isso motivado pelo racismo contra povos indígenas e em prol da colonização européia. E mais, a destruição dos cemitérios sagrados dos povos indígenas, que representam uma forte referência cultural, fez com que famílias perdessem definitivamente o elo com seus ancestrais. 


\section{Violência, migração e conseqüências}

Dando um salto cronológico na história, já no início do século $X X$, a violação aos direitos humanos dos povos indígenas continuava. E aqui contamos um caso particular, mas comum a milhares de brasileiros, migrantes indígenas. O índio Chico Sólon, pai das meninas Maria de Lourdes, Maria Isabel e Maria Soledad, foi assassinado cruelmente por combater a invasão das terras tradicionais no Nordeste. Amarraram-lhe pedras aos pés, enfiaram-lhe a cabeça em um saco e o arremessaram ao fundo das águas do litoral paraibano. A família colonizadora inglesa ainda assassinou muitos pais e avós de família. Quase 70 anos depois, a empresa foi à falência e nunca se fez justiça a esses crimes organizados, objetivando os interesses políticos e econômicos locais.

Amedrontadas, as filhas de Chico Solón e toda a família migraram para Pernambuco, também no Nordeste do Brasil. Por volta de 1928, nascia a pequena Elza, filha de Maria de Lourdes, fraquinha e enferma por causa das condições de vida de sua família. Pouco tempo depois, todos migraram de novo, então para o Rio de Janeiro, em um navio em condições subumanas que trazia nordestinos, indígenas e negros para o Sul do país. Sem conhecer ninguém - e paupérrima - a família indígena permaneceu uns tempos morando nas ruas. Quando Maria de Lourdes, índia, mulher, analfabeta, paraibana , nordestina e já separada do marido, conseguiu trabalho, estabeleceu-se com os filhos em uma área de prostituição, a Zona do Mangue, próxima à estação ferroviária da Central do Brasil, na Praça XI. Para que Maria de Lourdes pudesse trabalhar, a debilitada Elza tinha que tomar conta de seus dois irmãos. la à escola levando-os junto, um no colo e outro na mão.

No começo da adolescência, Elza acabou ficando seis meses de cama por uma doença nos ossos, causada pela pobreza nordestina e indígena. Mais ou menos oito anos depois, a jovem Elza casa-se e tem dois filhos: um menino e uma menina. Lamentavelmente, seu marido é atropelado por um bonde na cidade e morre, ficando órfãs as suas crianças. A história se repete na vida de Elza: só, como sua mãe Maria de Lourdes, e sofrendo todas as conseqüências de ser uma mulher sozinha na sociedade, onde o poder paterno e racista dominava.

Em 1956, quando a filha de Elza já tinha 6 anos de idade, Maria de Lourdes, mulher indígena, analfabeta, paraibana, nordestina e agora quase mão-de-obra escrava nas feiras cariocas, inicia o processo de criação da menina, para ajudar Elza, que era faxineira em uma firma. A menina foi criada a sete-chaves, dentro de um quarto semi-escuro, e quase nunca saía. Quando via o sol, desmaiava. As necessidades biológicas e os banhos eram feitos ali mesmo. A cozinha, apertada e fora da casa, era cenário das caçarolas expostas; os peixes e carnes-secas eram pendurados como se fossem roupas no varal, e eram constantes as presenças de mandioca, fruta-pão, inhame, banana-da-terra, frutas em geral. Presume-se que a índia Maria de Lourdes mantinha a pequena menina Poti no quarto para preservar sua identidade moral, física, psicológica e indígena. Viviam em uma área socialmente comprometida, onde também havia uma colônia de estrangeiros vindos da Europa, migrados em conseqüência da Segunda Guerra Mundial, composta por carvoeiros italianos, bananeiros portugueses e comerciantes espanhóis, além de brasileiros pobres e miscigenados.

Ali naquele pequeno mundo, ou melhor situando, naquele pequeno gueto indígena, a menina foi ouvindo as histórias indígenas de suas tias, tias-avós e mãe, todas mulheres indígenas, migrantes de suas terras originais. Com exceção de uma tia, todas casaram, e tempos depois os maridos iam embora ou morriam, deixando-as sozinhas com os filhos para criar e enfrentando o racismo e a intolerância da sociedade machista e preconceituosa. Por muitos anos, a menina teve essa história como cenário de vida, 
tornando-se uma pessoa muito observadora, calada, sensível e espiritualizada, herança das mulheres indígenas que, mesmo fora das terras originais e violentadas pelo processo histórico, político e cultural, mantiveram sua cultura e seus hábitos tradicionais, principalmente os seus laços com os ancestrais, a cosmologia e a herança espiritual.

Quando a menina começou a ir à escola, sua avó a levava e permanecia do lado de fora das grades, tomando conta, observando todas as ações da neta. A menina nunca podia falar com as outras crianças, não conseguia se relacionar ou brincar, principalmente porque as outras crianças a estigmatizavam por ser indígena e por sua avó não ter hábitos de uma avó urbana. Assim, com a cultura indígena recebida no gueto familiar e mais a dedicação que tinha aos livros, Poti foi crescendo. Sua avó, analfabeta, sempre pedia que escrevesse cartas a uma determinada pessoa da área indígena de origem e sempre chorava ao receber as respostas. E, por isso, bebia demais. Quando 'a encarcerada domiciliar' se tornou professora primária - o orgulho da família pobre, indígena e desaldeada -, a sua consciência crítica estava borbulhando. Ao tomar contato com a filosofia de educação do professor Paulo Freire, um dos maiores educadores populares do Brasil, perseguido pela ditadura militar e exilado, a menina, agora mulher, ganhou o mundo. Incentivada pelo cantor comunista Taiguara, também indígena de origem Charrua do Uruguai, com o qual se casara, fez o retorno ao inconsciente coletivo, visitando várias nações indígenas e perseguindo, sem medir esforços, a verdadeira história de sua tão sacrificada, marginalizada e racializada família migrante do Nordeste brasileiro.

Visitou as terras tradicionais de sua mãe, de sua avó, de seus ancestrais espirituais. Ali sentiu a essência da existência humana e espiritual. O seu cordão umbilical queimava e seus pés não andavam. Flutuavam... Foi aí que conheceu um senhor muito velho e cego, o índio Marujo, de uns 90 anos, que narrou como se deu a retirada daquela família no início do século. Procurou outros velhos índios que confirmavam a mesma história e lembravam de Chico Sólon, pai de sua avó. Essa avó, Maria de Lourdes, com apenas 13 anos, assim como outras meninas indígenas, já era mãe solteira, vítima de violação sexual praticada por colonos que trabalhavam para a família inglesa, que escravizava a população indígena no plantio do algodão.

Com esse testemunho, a nova cidadã, agora sabedora de suas raízes, tinha a certeza de que estava em casa e queria resgatar e preservar sua cidadania e abraçar sua terra indígena. Entrou para o movimento indígena, criou políticas de resistência, atuou em um trabalho de campo que beneficiou muitas pessoas, mas esbarrou com a força reacionária, política e econômica do local. Quase foi morta por querer noticiar os fatos arbitrários e trazer a conscientização dos direitos Indígenas para o povo potiguara, que, na época, sofria o impacto social e ambiental do arrendamento de suas terras por fazendeiros inescrupulosos que promoviam o racismo ambiental. Sofreu humilhações públicas, ameaças de morte, extorsões, inclusive difamação em vários jornais da Paraíba. Sofreu abuso sexual, prejudicando sua imagem moral, afetando seu trabalho, seu estado psicológico e de seus filhos e prejudicando sua Organização.

A Rede Globo de Televisão anunciou uma lista dos marcados para morrer e lá estava o nome dessa cidadã. Para não prejudicar a imagem histórica, política e social de seu povo, teve que se calar, pois havia indígenas envolvidos no arrendamento ilegal das terras. Foi obrigada a depor na Polícia Federal, acusada de incitar lideranças, de captar recursos internacionais para 'comprar' consciências e de falsidade ideológica, isto é, por estar assumindo sua identidade indígena, herança de sua mãe e avós. Os recursos vinham do Programa de Combate ao Racismo do Conselho Mundial de Igrejas, o mesmo programa que apoiava, na época, Nelson Mandela. Os recursos financeiros vinham também da Associação de Povos Ameaçados de Luxemburgo e da Unesco da França, para a 
construção da Casa da Mulher Indígena e a produção do Jornal do Grumin e cartilhas de conscientização e desenvolvimento de projetos comunitários. No entanto, as lideranças legítimas, os velhos, a mulher mais velha da tribo, Tia Severina, e os caciques não abandonaram essa mulher. Todos foram acompanhá-la à Polícia Federal. Dias mais tarde, deporia na Procuradoria de Estado, e Maria de Fátima Potiguara, uma índia xamã, e coordenadora local do Grumin, afirmou para o doutor Luciano Maia, na época procurador da Paraíba: "Onde Eliane Potiguara cair, todas nós, mulheres desse povo, iremos de caminhão, abriremos um buraco e cairemos todas lá!"

Esse depoimento e a ação internacional do Pen Club da Inglaterra, que mobilizou escritores que lutam pelos direitos humanos e organizações afins, fizeram parar as ameaças. Cartas e ofícios de solidariedade chegaram ao presidente do Brasil, Collor de Melo, ao Governo do Estado, à Prefeitura local e à FUNAl. Mas a violação aos Direitos Humanos dessa mulher indígena permaneceu como uma cicatriz profunda, porque nunca a justiça realmente se fez, e as mulheres de sua família vão levando para o túmulo esse legado.

\section{Similaridade das histórias}

Analisando essa história contada acima, que se passou no transcorrer do século XX, percebemos que a causa principal dos conflitos, dissabores, amarguras e solidão está lá, no início da colonização, e que a violência, o racismo e a intolerância aos direitos indígenas têm se arrastado ao longo do tempo, prejudicando dezenas de vidas e relações interpessoais. Assim, está formalizada a história de muitos indígenas que se separaram de seu território tradicional e de suas famílias. Esse é um caso a ser estudado também, para que se constitua um inquérito a partir de estudos antropológicos, baseados em histórias e testemunhos, para que se consiga resgatar a dignidade e a cidadania dessas famílias vítimas de racismo, exploradas e escravizadas por processos colonizadores em todo o território nacional, assim como também o foram os Povos Ressurgidos e os Quilombolas. Essa história não pode ficar nas vitrines. Esses gritos não podem somente ecoar ou ir para o túmulo. A história narrada acima não é incomum - já aconteceu com muitos indígenas, como nos casos de Marçal Tupã, de Ângelo Kretã, de Hibes Menino e de outros anônimos que deixaram suas filhas e esposas à mercê dos assassinos. Por isso, queremos dar visibilidade à história.

Anestesiada pelo paternalismo oficial dos órgãos públicos, que administram a questão indígena desde a 'descoberta do Brasil' até hoje, a esmagadora maioria de famílias indígenas violentadas nas aldeias onde vivem, ou desaldeadas e desestruturadas, permanece calada, por pressão política, social e econômica ou por desconhecer os seus Direitos Humanos. E esse paternalismo sempre foi uma forma de racismo. O racismo institucional.

Esse tipo de violência e racismo, isto é, a migração dos povos indígenas de suas áreas tradicionais, merece um estudo, assim como a situação das mulheres indígenas no Brasil, que sofrem abuso, assédio, violência sexual, que se tornam objeto de tráfego nas mãos de avarentos e degradados nacionais e internacionais. Essa é a causa que estamos levantando!

No mundo inteiro, os conflitos entre povos e o poder têm causado migrações, desplazamientos (povos obrigados a deslocar-se e a fugir por algum motivo, sejam guerras locais ou guerras internacionais, conflitos de raça, etnia). Muitas consciências já se levantaram contra essa situação e, principalmente, contra as conseqüências desses deslocamentos de povos de seu habitat natural, constituindo-se no chamado racismo ambiental. Muitos organismos das Nações Unidas têm tratado desse ponto com considerável atenção, mas ainda estão aquém do que seria necessário. E a mulher e as crianças são os 
mais atingidos nesse caso. A violação aos seus Direitos Humanos tem conduzido mulheres indígenas às mãos de homens corruptos que as seduzem por um prato de comida, por programas, promessas eventuais que confundem o universo feminino, pois tais mulheres têm sua origem em uma cosmovisão com valores e tradições totalmente diferentes do mundo urbano e masculino envolvente. Esse tem sido o caso de mulheres yanomami conduzidas à prostituição e ludibriadas por soldados ou comerciantes. Recentemente, um chefe indígena no Brasil Central passou por uma situação muito humilhante entre os parentes de seu povo, quando sua esposa partiu com um comerciante local não-indígena.

Em suas comunidades, as mulheres indígenas são iludidas pelo encantamento e pelas condições da sociedade envolvente, haja vista que centenas e centenas delas saem de suas casas para a insegurança das cidades próximas ou das grandes cidades. Isso constitui tráfico de mulheres, como se constata nos prostíbulos, nas zonas de baixo meretrício onde vendem seus corpos por migalhas, contraindo Aids e outras doenças, criando crianças sem futuro, famintas ou portadoras de HIV. A maioria vai ser empregada doméstica, mão-de-obra quase escrava, como atesta o depoimento da índia Deolinda Prado dado ao Grumin, há quase 20 anos, que motivou a criação do primeiro núcleo de apoio a empregadas indígenas em Manaus. As mulheres indígenas também trabalham como operárias mal remuneradas ou trabalham nas grandes plantações dos latifundiários, em um sistema de cativeiro, trocando trabalho por latas de sardinha e nunca conseguindo pagar sua dívida com o contratante. Muitas vezes, trabalham somente pelo prato miserável de comida ou por um pouco de farinha de mandioca. As que vão morar com homens sem caráter são transformadas em objeto de cama e mesa, submetidas a agressões físicas e a parir dezenas de filhos para viver miseravelmente nas palafitas da Amazônia, dentro e fora do Brasil, nas favelas contaminadas, moral, social, política e fisicamente.

Atualmente, com o apelo da comunicação de massa, muitas meninas e adolescentes querem projetar-se nos loiríssimos símbolos sexuais das grandes redes de televisão, modelos de beleza brasileira que deixam os homens enlouquecidos. É o que acontece com centenas de mulheres indígenas que se dirigem a Manaus, Belém, Boa Vista, Recife, Brasília, São Paulo, Rio de Janeiro e demais Estados do Brasil, para tentarem ser também essas insinuantes loiras da mídia. Muita gente desatenta pode criticar, conduzindo seu raciocínio para um julgamento injusto, do seguinte tipo: "Essa população, então, não preserva mais os seus valores, já quer o mundo da sociedade envolvente!" 0 sistema político deveria garantir a dignidade, a preservação cultural e o direito territorial dos povos indígenas, mas não o faz. A Constituição, uma vitória nossa, ainda está aquém. Urge um Estatuto do Índio, criado, discutido e planejado pelos Povos Indígenas do Brasil que, há séculos, sobrevivem em um clima constante de insegurança, sem saber se o local onde estão enterrados seus mortos será, no futuro, o território de seus filhos!

Os instrumentos jurídicos internacionais resultantes das Cumbres e das Conferências Internacionais das Nações Unidas estão aí para serem aplicados pelos governos. Mas a cada vitória da população oprimida do mundo corresponde uma nova batalha para que os governos ponham em prática os direitos conseguidos. Tendo em vista os testemunhos como os citados acima e a referência política acerca da violação dos Direitos Humanos dos Povos Indígenas no Brasil, o engajamento do movimento indígena nacional no processo da Conferência Mundial contra o Racismo foi extremamente importante e histórico. Mais uma vez, as mulheres deram o passo inicial nesse processo político. 


\section{Os caminhos políticos na construção da participação indígena na III Conferência}

Os caminhos políticos para construir a participação dos Povos Indígenas na Conferência Mundial contra o Racismo foram vários, considerando o leque de organizações que compõem o movimento indígena nacional. Cada organização indígena, com sua história e prática, contribuiu para essa participação, na medida em que elas já vinham reivindicando seus direitos junto ao Governo Federal, órgãos estaduais e municipais. Esses espaços de interlocução foram conquistados com a luta do dia-a-dia, nas aldeias indígenas, nos fóruns locais, estaduais, nacionais e internacionais, ao longo dos últimos 20 anos de trabalho de líderes indígenas vivos até hoje, ou assassinados como os referidos acima. Isso sem desconsiderar a liderança de homens e mulheres anônimos ou conhecidos que se esforçaram e sofreram ameaças até de morte para construir as bases dessa participação na Conferência. É importante ressaltar que não foi uma ou outra pessoa individualmente que construiu esse processo de participação, mas sim uma história, uma luta, um processo polêmico, sacrificado e humilhado, em que os atores principais foram velhos, velhas, homens, mulheres, jovens e crianças indígenas. As lideranças presentes em Durban foram apenas porta-vozes naquele momento. Essa luta foi construída por várias vozes indígenas, por mães nacionais, progenitoras de muitos índios Galdinos, por muitos Chicos Sólons, avós potiguaras!

A inclusão da denominação "Povos Indígenas" nos documentos oficiais, a ratificação da Convenção 169 da Organização Internacional do Trabalho (OIT), a solicitação de espaços de participação, cotas e inclusão da questão indígena nos Conselhos e nos Ministérios, a demarcação e homologação das terras indígenas Raposa Serra do Sol e outras terras polêmicas, a reivindicação de um Estatuto do Índio que parta da realidade atual dos Povos Indígenas, entre outras, são exigências que nós, Povos Indígenas, temos feito em todos os Fóruns nacionais e internacionais. Elas têm sido discutidas, principalmente, no Grupo de Trabalho sobre Povos Indígenas que, há 20 anos, trata da Declaração Universal dos Direitos Indígenas, e onde nós, particularmente, participamos como porta-voz em dezenas de sessões na ONU/Genebra.

Em outros países, os caminhos políticos de construção da participação na Conferência Mundial sobre Racismo não foram muito diferentes do processo brasileiro. A diferença foi apenas estrutural, não nos conteúdos e nas reivindicações de cada país, pois a similaridade entre eles é muito grande. Há de se considerar os avanços políticos referentes à questão indígena, como é o caso do Equador, onde a maioria indígena vem realmente conquistando seus direitos e espaços, embora sofrendo as conseqüências de seus avanços. Ainda nos deparamos com os indígenas mapuche, do Chile, presos por lutar por sua cidadania contra o sistema de racismo, assim como com os da Guatemala. Rigoberta Menchu, Prêmio Nobel da Paz, recentemente desafiou o governo contra a migração de indígenas. No Brasil, a migração está invisibilizada e a população indígena está aumentando nas cidades interioranas e litorâneas, e a mulher indígena está cada vez mais pobre e mais enferma, em conseqüência da migração, do racismo e da intolerância que aí se encerram.

Quanto à questão de gênero, a luta tem sido dobrada pelo preconceito, pelo desconhecimento e pelo desinteresse dos envolvidos, o que contribui para tornar invisível a situação das mulheres indígenas no Brasil. Por isso, para falar da participação das mulheres indígenas na Conferência Mundial contra o Racismo, há um outro histórico que não pode ser ignorado. 
Em 1986, o Grumin surgiu em uma assembléia na área indígena potiguara, na Paraíba. Após vários debates locais, cursos de capacitação, Seminário Nacional e Conferências Internacionais que realizamos, chega-se à crítica conclusão de que não existem estudos, cifras, estatísticas que documentem as maneiras como as mulheres indígenas estão sendo ameaçadas e violadas em seus Direitos Humanos, e a maneira pela qual elas podem estar se extinguindo devido à mortalidade materna, à mortalidade por violência física, por migração de suas terras indígenas e por conflitos culturais e políticos que ameaçam suas vidas, suas famílias e o direito ao território indígena e à sua cosmovisão. Há dez anos, quando o Grumin levantava a bandeira contra a invisibilidade da mulher indígena, a antropologia, a lgreja, as ONGs e o Estado conservadores nos olhavam como inconseqüentes por falar em saúde e direitos reprodutivos. Acreditavam que esse assunto era alheio à cultura indígena e influenciado pelo movimento feminista!

Nós mesmas sentíamos os olhares questionadores quando distribuíamos o polêmico Jornal do Grumin, em um encontro sobre hidrelétricas, em Altamira, Pará. Lembro que um líder indígena nos mandou ir para a cozinha ou ficar fora das assembléias segurando os filhos no colo, inclusive o dele! Mas a guerreira Tuíra mostrou o facão para um empresário, dono da hidrelétrica que ameaçava a vida dos kaiapós do Pará. Acredito que aí se abriu uma brecha para a mulher indígena, embora ainda hoje tenhamos que pressionar para que as políticas públicas incluam a questão de gênero.

Também lembro como uma minoria de cientistas sociais, da lgreja ou não, sutilmente, causava intrigas entre nós, indígenas, por sermos urbanos, aldeados do Nordeste ou desaldeados. A discriminação contra nossa consciência era enorme, principalmente quando vínhamos das cidades ou éramos formados. Imaginem! A antropologia do passado próximo valorizava somente os aspectos culturais de um povo e os analisava estruturalmente, sem considerar os antecedentes políticos. Era uma antropologia burguesa baseada no preconceito de que só eram indígenas aqueles que viviam desnudos nas terras longínquas e sonhadoras do Brasil. Nós tínhamos nossas terras, mas fomos acuados para as cidades! Nossos avós foram assassinados. Não somos culpados. De vítimas passamos a ser discriminados e chamados de oportunistas.

A exclusão cultural, a invisibilidade histórica, os avanços, derrotas e desafios faziam com que buscássemos caminhos de conscientização através de cursos de capacitação, de consultas nacionais, seminários sobre cidadania, família e direitos reprodutivos. Nós nos fortalecíamos nas feiras de artesanato e nos projetos de desenvolvimento comunitário. Também utilizávamos cartilhas, jornais, panfletos e livros para a conscientização contra o alcoolismo, a violência, a desinformação, o analfabetismo, a ignorância de não querermos preservar e resgatar a identidade indígena, por vergonha que tínhamos de nós mesmos! Éramos bugres, índios, pessoas sujas e preguiçosas carregando uma imensa cabeleira de crina de cavalo, cheia de piolhos! Assim o racismo imperial impunha o que ele quer que sejamos.

Nossas ações eram estratégias para trazer essas questões à tona. Isso foi um desafio para os povos indígenas, pois os vícios e as condições impostos pelo colonizador estão enraizados: desinformação, analfabetismo, dificuldades de falar sobre sexo, alcoolismo, incesto e gravidez prematura, desequilíbrio emocional e psicológico causado pelas invasões das terras e ameaças de sobrevivência, a falta de alimentos, roupas e medicamentos, 0 desprestígio das parteiras, o desprestígio dos pajés, dos caciques, as intrigas, entre outros fatores.

As diversas lutas nacionais e internacionais que empreendemos pelos direitos humanos dos povos indígenas - desenvolvimento sustentável de cada nação, reconhecimento oficial dos direitos à propriedade intelectual e conhecimentos tradicionais, 
preservação da biodiversidade indígena e a lei das patentes, entre outras - permitiram a construção temática e política que motivaria a participação indígena na III Conferência contra o Racismo. E embora muita coisa tenha ficado sem ser feita, não nos arrependemos, pelo contrário, pois temos que acompanhar o ritmo da história e ir por etapas.

\section{Contribuições da Conferência para as questões indígenas no Brasil e em outras partes do mundo}

A participação dos povos indígenas na Conferência Mundial sobre Racismo contribuiu para a conscientização, para a unidade indígena em nível nacional e internacional, para o intercâmbio político-cultural e para incentivar os povos a continuar suas lutas locais, nacionais e internacionais. Em Durban, também estiveram representantes indígenas que hoje participam de uma conquista nossa dentro do sistema Nações Unidas, o chamado Fórum Permanente para os Povos Indígenas, cuja primeira reunião vai acontecer em maio de 2002, em Nova York.

No Brasil, a Conferência contra o Racismo impactou na medida em que as pessoas indígenas, cada vez mais, tornam-se conscientes de seus direitos e sabem onde podem buscar apoio. Hoje, os olhos da sociedade já não estão tão cegos. Já existem mecanismos e instrumentos jurídicos que os povos podem utilizar para a defesa de seus direitos. É claro, muita luta ainda existe, mas a Conferência continua ecoando, e o documento final produzido neste grandioso evento certamente será utilizado como recurso para pressionar os governos a implantar iniciativas favoráveis aos nossos direitos. Uma dessas iniciativas é o sistema de cotas e a inclusão de uma representante indígena no Conselho Nacional de Educação

Por isso, é importante que se façam cartilhas facilitadas, coloridas com ilustrações dentro da prática de cada um, sobre o documento de Durban, pois o documento final é longo e de difícil leitura. Como contribuição à Conferência Mundial contra o Racismo, o Grumin coloca alguns pontos em relação às mulheres e aos homens indígenas, que não são contemplados na prática, mas que podem facilitar a discussão e a implementação de mudanças na realidade atual dos povos indígenas. Os pontos de discussão e as sugestões apresentados a seguir não foram criados ou imaginados, não são estáticos; são dinâmicos e partiram de observações e conversas ao pé do ouvido. Nada técnico ou científico. Apenas real, apenas palavras não contadas. Acreditamos que tais referências possam ser analisadas, discutidas e servir para futuras investigações científicas, ações políticas, medidas legislativas, sociais, educativas e administrativas, enfim, ações afirmativas para Povos Indígenas. Os pontos são:

\section{Conhecimentos Tradicionais e Patrimônio Cultural}

Que as mulheres indígenas curandeiras, líderes espirituais e os próprios pajés sejam valorizados pelas políticas públicas como conhecedores milenares da tradição indígena.

Que o conhecimento ancestral sobre ervas medicinais seja uma prioridade em benefício da saúde e da integridade da mulher, da comunidade e da humanidade. Que as cerimônias de cura sejam respeitadas pelas políticas públicas

Que a espiritualidade feminina possa ser resgatada, reconhecida dentro e fora da cultura e exercida sob a forma de pajelança que foi abafada pela imposição da lgreja, no período da colonização. 


\section{Violência}

Que as mulheres possam buscar socorro em caso de violência doméstica causada por alcoolismo de seu marido, pais ou irmãos e que possam falar sobre esse assunto sem receberem represálias.

Que as adolescentes e meninas sejam esclarecidas sobre incesto, assédio, abuso e violência sexuais ou estupro, tenham acesso garantido à defesa legal e não sejam obrigadas a esconder o fato por medo, pena ou risco de vida, mesmo dentro das áreas indígenas.

Que seja garantido o tratamento das conseqüências psicológicas da violência - física, moral ou resultante de estupro - como silêncio por medo, silêncio por não conhecer os seus direitos, alcoolismo, loucura, violência feminina com as crianças, etc.

\section{Saúde Integral e Direitos Reprodutivos}

Que os agentes de saúde sejam na maioria indígenas e, se não, que sejam sensibilizados para tal.

Que as mulheres indígenas e seus filhos tenham acesso facilitado e garantido à saúde integral, através das políticas públicas.

Que as políticas públicas reconheçam os direitos reprodutivos das mulheres indígenas de acordo com as tradições e culturas, desde que essas culturas não violentem as mulheres.

Que os métodos tradicionais de controle de natalidade, assim como as decisões culturais sobre a concepção e o parto, sejam reconhecidos nos serviços públicos, caso a mulher recorra a eles.

Que a esterilização depois do segundo ou terceiro filho não seja imposta pelas políticas públicas e que a cesariana não seja uma imposição dos médicos.

Que as mulheres e as jovens não sejam obrigadas ao aborto clandestino que as leva à morte e às enfermidades irreversíveis.

Que os adolescentes, meninos e homens possam ser instruídos sobre o ato de concepção, responsabilidades paternas e as responsabilidades políticas na preservação da cultura e na garantia da identidade indígena.

Que os homens e as mulheres indígenas possam ter acesso às informações sobre Aids e outras doenças sexualmente transmissíveis.

Que todos os documentos produzidos pelo Movimento Indígena Brasileiro, órgãos governamentais locais ou nacionais contenham medidas em defesa dos Direitos Humanos das mulheres e seus direitos reprodutivos e que proponham ações afirmativas pela melhoria da qualidade de vida.

\section{Conclusão}

Em resumo, o governo deve reconhecer, na prática, o fator pluricultural e diferenciado dos Povos Indígenas, incluindo os direitos relativos a gênero, direitos sexuais e reprodutivos 
das mulheres indígenas, como foi discutido na Conferência Mundial contra o Racismo. As terras indígenas devem ser definitivamente demarcadas como garantia da integridade física, social, cultural, econômica e psicológica dos povos indígenas e, em particular, das mulheres - velhas, viúvas e mães solteiras. Os invasores devem ser definitivamente retirados para garantir a sobrevivência e segurança das mulheres, das crianças e das(os) mais velhas(os).

Os programas nacionais de desenvolvimento aplicados à mulher devem ser estendidos às mulheres indígenas, desde que a comunidade seja consultada e dentro do que espera e necessita esse povo. É necessário especificar detalhadamente medidas emergenciais que defendam em curto prazo os direitos das mães solteiras, viúvas e mães anciãs contra a violência doméstica e social.

A Conferência Mundial contra o Racismo, Discriminação Racial, Xenofobia e Intolerâncias Correlatas, vitoriosamente, teve sua marca peculiar. Foi a maior e mais expressiva Conferência em todos os tempos. Que possamos verdadeiramente colher os frutos em prol dos Direitos Humanos em todas as partes do mundo. 